\title{
Orstomella yaliuensis n. sp., a xarifiid copepod (Crustacea) parasitic in the polyps of hump coral Porites lutea Milne Edwards \& Haime off Taiwan
}

\author{
Yu-Rong Cheng $\cdot$ Ju-shey Ho $\cdot$ Chang-Feng Dai
}

Received: 20 January 2009/ Accepted: 12 February 2009

(C) Springer Science+Business Media B.V. 2009

\begin{abstract}
A new species of xarifiid copepod, Orstomella yaliuensis $\mathrm{n}$. sp., is described. It was found living in the polyps of a scleractinian coral, Porites lutea Milne Edwards \& Haime, collected off Yaliu in the northern part of Taiwan. The new species can be distinguished from its two congeners, $O$. faviae Humes \& Ho, 1968 and O. lobophylliae Humes \& Ho, 1968, by the presence of five (rather than six) segments on the antennule, a spine only (rather than a seta and a spine) at the tip of the antenna, a uniramous leg 2 , and a relatively long (rather than short) spine at the tip of the caudal ramus.
\end{abstract}

\section{Introduction}

So far as we are aware, three species of copepods have been reported occurring in symbiosis with hump coral Porites lutea Milne Edward \& Haime. They are: Monomolgus tortulus Humes, 1984, Kombia incrassata Humes, 1984 and K. curvata Nair \& Pillai, 1985. The first two species were collected from off French Polynesia in the South Pacific (Humes, 1984) and the

Y.-R. Cheng · C.-F. Dai

Institute of Oceanography, National Taiwan University, Taipei 106, Taiwan

J.-s. Ho $(\square)$

Department of Biological Sciences, California State University, Long Beach, California 90840-3702, USA

e-mail: jsho@csulb.edu last species from the Gulf of Mannar in the Indian Ocean (Nair \& Pillai, 1985). They are all members of the Rhynchomolgidae Humes \& Stock, 1972, which is the largest family of poecilostomatoid copepods associated with invertebrate hosts, with most of its members occurring in association with cnidarians, especially alcyonarians (Ho \& Kim, 2001).

In this paper, we add a new species of poecilostomatoid copepod from off Taiwan to the list of the symbionts of $P$. lutea. It belongs to a different family, the Xarifiidae Humes, 1960. Unlike rhynchomolgids, xarifiids occur exclusively in the gastrovascular cavities of scleractinian corals. Furthermore, whereas rhynchomolgids are widely distributed throughout the tropical and subtropical oceans of the world, xarifiids are confined to the Indo-West Pacific and have not been reported from the corals of the Atlantic or Central and Eastern Pacific (Humes, 1985).

\section{Materials and methods}

Fragments of hump coral $P$. lutea were collected by SCUBA diving at a depth of $3 \mathrm{~m}$, placed in a plastic bag while in the water, and transported to the laboratory for the examination of copepod parasites. To collect xarifiids, the coral, together with the seawater in the bag, were emptied into a bucket to which sufficient $95 \%$ ethanol was added to make it an approximately 5\% solution. After several hours, the copepods had abandoned the coral polyps and then 
fallen to the bottom of the container. The water was then poured through a $100 \mu \mathrm{m}$ mesh net. Copepods were picked from the sediment retained in the net and preserved in $70 \%$ ethanol. They were later cleared in $85 \%$ lactic acid for $1-2 \mathrm{~h}$ and dissected on a wooden slide under a dissecting microscope (Humes \& Gooding, 1964). The removed body parts and appendages were examined under a compound microscope with a series of magnifications up to $1,000 \times$. All drawings were made with the aid of a drawing tube fitted on an Olympus BH microscope.

\section{Orstomella yaliuensis n. sp.}

Type-host: Porites lutea Milne Edward \& Haime (hump coral) (Poritiidae).

Type-locality: Off Yaliu, Taiwan.

Site: Inside gastrovascular cavity.

Material studied: Four 우우 and 1 ô (missing posterior half of body) obtained from a colony of hump coral collected at $3 \mathrm{~m}$ depth on 28 September, 2006.

Type-material: Holotype (NTUIO-COPEPOD 0008) and allotype (slide, NTUIO-COPEPOD 0009) are deposited in the Institute of Oceanography, National Taiwan University, Taipei, Taiwan. Remaining specimens (dissected) are retained in the first author's private collection.

Etymology: The species is named after the typelocality Yaliu (in Taiwanese).

\section{Description (Figs. 1-2)}

\section{Female (Fig. 1A-M)}

Body (Fig. 1A, B) elongate, $1.28(1.22-1.38) \mathrm{mm}$ long and $0.24(0.20-0.28) \mathrm{mm}$ wide, based on 4 specimens. Body segmentation distinct, except for cephalothorax where first pediger appears incompletely fused to cephalosome. Fifth pediger almost as large as metasomal somites (Fig. 1A, B), appearing incompletely fused to fourth pediger in lateral view (Fig. 1B). Genital double-somite distinctly narrower than fifth pediger, inverted pyriform with wider anterior half containing egg-sac attachment area on dorsolateral side (Fig. 1A). Egg-sacs not seen. Abdomen (Fig. 1C) 3-segmented and slightly flexed ventrally; first somite largest. Caudal ramus (Fig. 1D) small, longer than wide, $20.27 \times 15.26 \mu \mathrm{m}$; bearing
Fig. 1 Orstomella yaliuensis n. sp., adult female: A. habitus, dorsal; B. habitus, lateral; C. urosome, lateral; D. caudal ramus, dorsal; E. antennule, anterior; F. antenna, anterior; G. labrum, ventral; H. maxillule, anterior; I. maxilla, anterior; J. maxilliped, posterior; K. leg 1, anterior; L. leg 2, anterior; M. leg 5, lateral. Scale-bars: A, B, $200 \mu \mathrm{m} ; \mathrm{C}, 0.1 \mathrm{~mm}$; D-M, $20 \mu \mathrm{m}$

2 tiny setae and 1 large, terminal spine, nearly twice as long as ramus itself.

Rostral area round in dorsal view, without snoutlike ventral lobe. Antennule (Fig. 1E) short, 5segmented; armature formula: $0,3,6,3$ and 7 . Antenna (Fig. 1F) 3-segmented, asetose, with broad first segment and long second segment; curved terminal spine longer than terminal segment. Labrum (Fig. 1G) with smooth posterior margin and slightly protruded posterolateral corners. Mandible and paragnath absent. Maxillule (Fig. 1H) a small lobe, tipped with 3 broad elements. Maxilla (Fig. 1I) 2segmented; proximal segment large and unarmed; distal segment a small, conical process bearing 3 setae, with 2 on anterior surface and 1 on posterior surface. Maxilliped (Fig. 1J) 3-segmented; proximal segment broadest, unarmed; middle segment with 1 short, obtuse seta and 1 large, pointed spine in mediodistal corner; distal segment smallest, tipped with 1 simple seta and 1 obtuse element with hyaline lamellae.

Leg 1 (Fig. 1K) biramous and legs 2 (Fig. 1L), 3 and 4 uniramous. All legs with 2-segmented exopod. Endopod on leg 1 much smaller than exopod (Fig. 1K). Formula of spines (in Roman numerals) and setae (in Arabic numerals) as follows:

\begin{tabular}{lllll}
\hline & Coxa & Basis & Exopod & Endopod \\
\hline Leg 1 & $0-0$ & $1-0$ & $1-0 ; 1, \mathrm{I}$ & $0-0 ; \mathrm{I}$ \\
Leg 2 & $0-0$ & $1-0$ & $\mathrm{I}-0 ; \mathrm{I}$ & Absent \\
Leg 3 & $0-0$ & $1-0$ & $\mathrm{I}-0 ; \mathrm{I}$ & Absent \\
Leg 4 & $0-0$ & $1-0$ & $\mathrm{I}-0 ; \mathrm{I}$ & Absent \\
\hline
\end{tabular}

Leg 5 (Fig. 1M) reduced to 3 obtuse setae inserted on lateral surface of fifth pediger (Fig. 1C). Leg 6 not seen.

\section{Male (Fig. 2A-E)}

Body, judging from available anterior half (Fig. 2A, B), elongate as in female. Antennule (Fig. 2C) generally as in female, except with additional seta on fourth segment. Maxilliped (Fig. 2D) 4-segmented; first and 

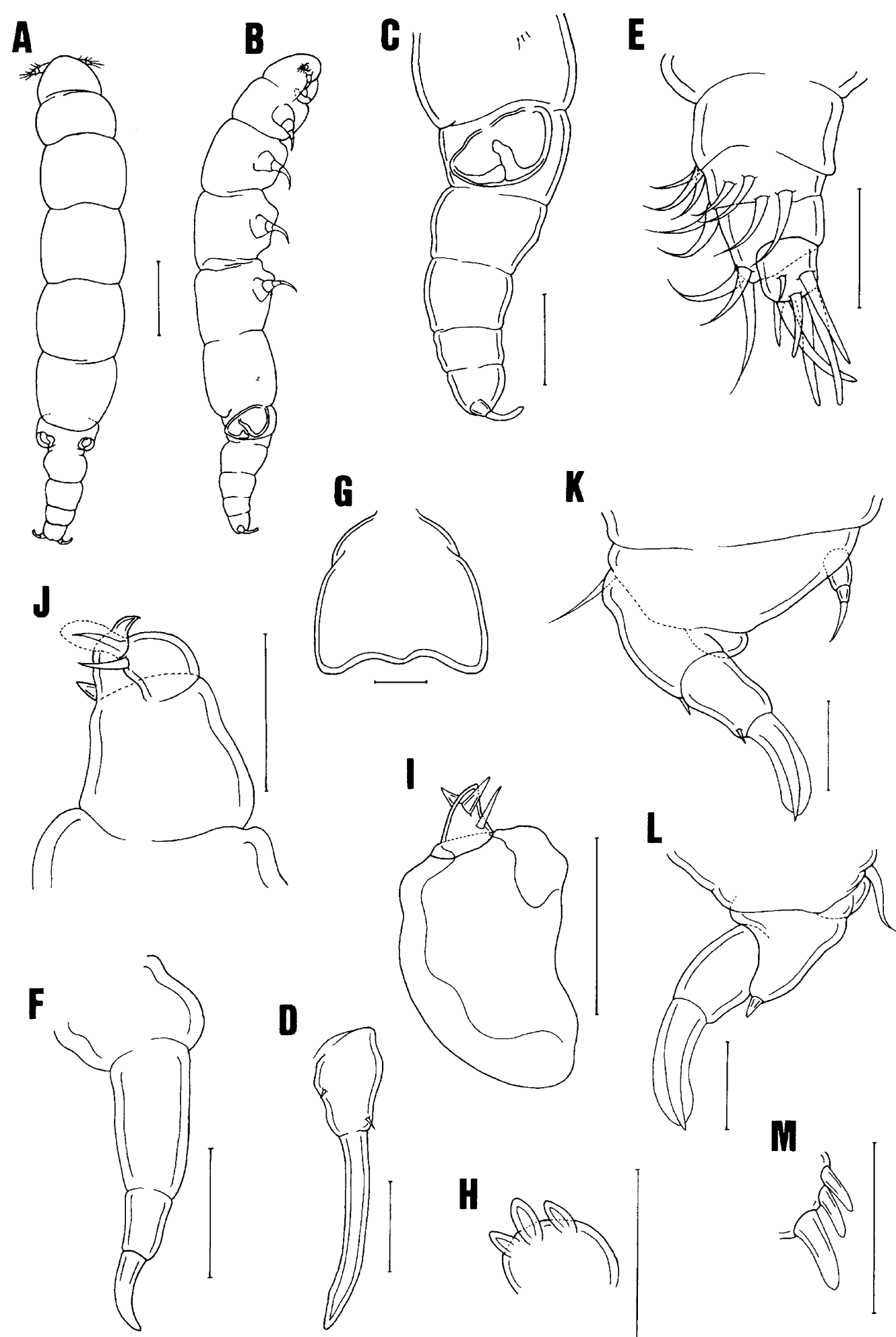

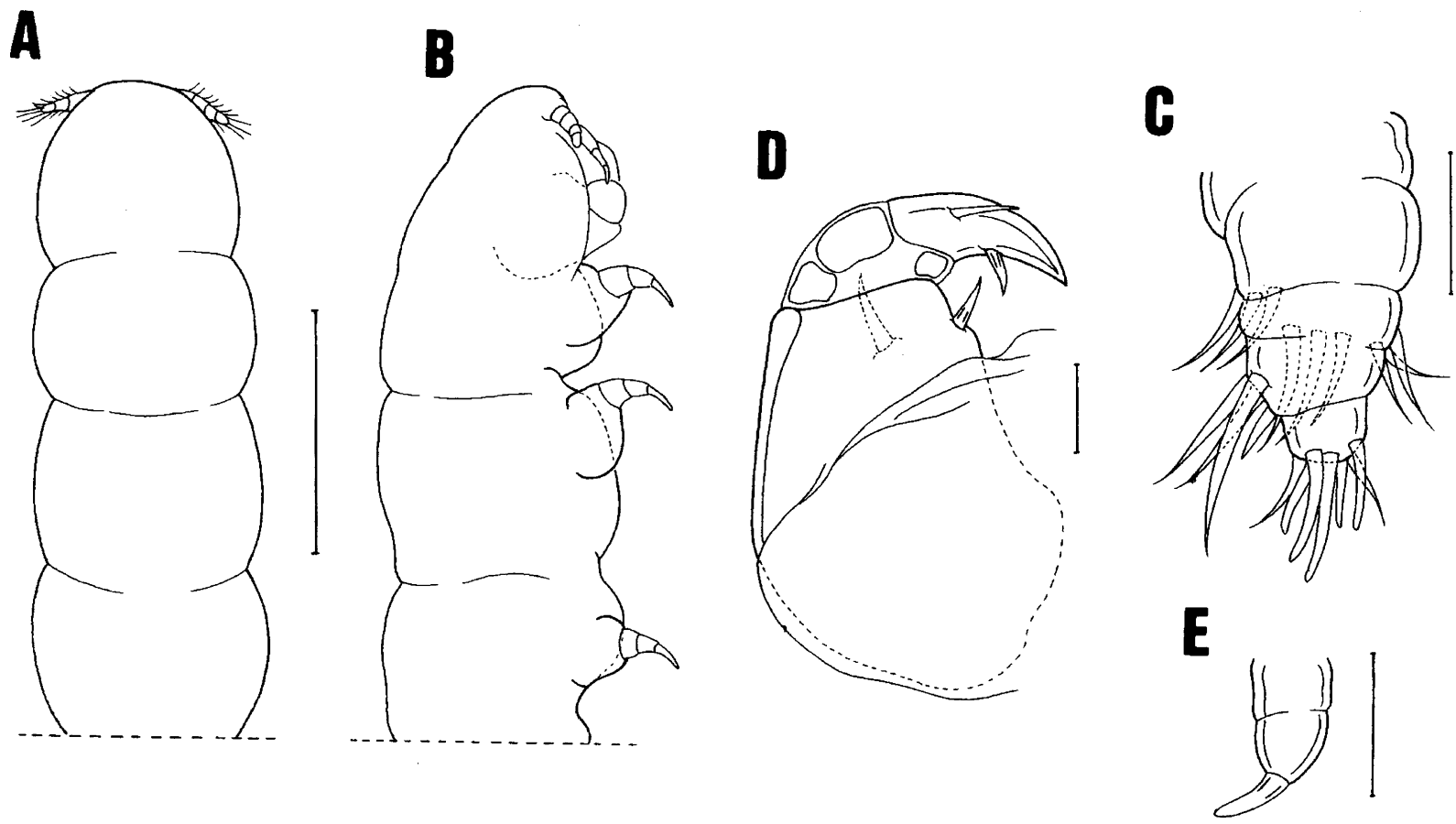

Fig. 2 Orstomella yaliuensis n. sp., adult male: A. prosomites 1-3, dorsal; B. same, lateral; C. antennule, anterior; D. maxilliped, posterior; E. leg 1 endopod, anterior. Scale-bars: A, B, $200 \mu \mathrm{m}$; C-E, $20 \mu \mathrm{m}$

third segments unarmed; second segment with 2 medial spiniform setae; fourth segment a pointed, robust claw with 1 simple basal seta and 1 medial spiniform seta. Legs 1-3 constructed as in female. Endopod of leg 1 (Fig. 2E) 2-segmented as in female but terminal element blunt-tipped. Legs 4 and 5 not available.

\section{Discussion}

With the lack of dorsal body processes on the fifth pediger, the absence of the mandible and the possession of a pair of uniramous legs (exopods only) on the third and fourth pedigers, the xarifiid specimens collected from Porites lutea off Taiwan is clearly a member of Orstomella Humes \& Ho, 1968. So far, only two species of Orstomella are known, O. faviae Humes \& Ho, 1968 and O. lobophylliae Humes \& Ho, 1968, taxa recovered from the coral families Faviidae and Mussidae, respectively, off Madagascar (Humes \& Ho, 1968). The host of our specimens belongs to another coral family, the Poritidae. Thus, each of the three different host families harbours its own species of Orstomella.
The two congeners of $O$. yaliuensis n. sp. are quite different in the structure of the antennule, according to Humes \& Ho (1968). It is 5-segmented in the new species but 6-segmented in both Madagascan species. Furthermore, the first segment of the antennule is a simple, unarmed segment in the Taiwanese species, but bears a prominent, anterior process in both Madagascan species. Another distinct difference between the Madagascan forms and the Taiwanese species is the structure of the caudal ramus. In the former it is tipped with a short spine (shorter than the ramus); but the same spine in the Taiwanese species is long, about twice as long as the ramus. These and some other differences between the three congeners are summarised in Table 1.

Additionally, some minor differences are detected between these three species of Orstomella. For instance, in the new species the shape of the setae on the pre-distal segments of the antennule is pointed (vs. obtuse), the labrum is unarmed (vs. armed with a pair of setule-bearing papillae), the maxillule is tipped with three simple elements (vs. two simple elements or three with a different structure), the outer seta of leg 1 is long, the endopodal segments of leg 1 are small, the distal element of legs 2-4 are longer 
Table 1 Differences between the three species of Orstomella Humes \& Ho, 1968

\begin{tabular}{llll}
\hline & O. faviae & O. lobophylliae & O. yaliuensis n. sp. \\
\hline Antennule & $\begin{array}{c}\text { 6-Segmented; basal segment with } \\
\text { anterior process; all setae identical }\end{array}$ & $\begin{array}{c}\text { 6-Segmented; basal segment with } \\
\text { anterior process; with 3 } \\
\text { modified setae }\end{array}$ & $\begin{array}{c}\text { 5-Segmented; basal segment } \\
\text { unarmed; all setae identical }\end{array}$ \\
Antenna & With basal, jointed seta; tipped & $\begin{array}{l}\text { Without basal seta; tipped } \\
\text { with seta and spine }\end{array}$ & With seta \& spine \\
Caudal ramus & Tipped with short spine & Tipped with short spine & Without basal seta; tipped \\
Leg 2 & Biramous & Biramous & Tipped with long spine \\
\hline
\end{tabular}

than the segment carrying it, of the three elements representing leg 5 the ventral (rather than the middle) one is the longest, and the caudal ramus is only 1.33 (vs. 2 or 3 times) as long as wide.

Acknowledgements We thank Shang-Yin Liu, Ming-Jay Ho, Anyi Cheng, Sharon Horng, Tsai-Ming Lu and Cheing-hwa Huang for their assistance in the field. This study was partly supported by a grant from the National Science Council and the Fisheries Administration of the Council of Agriculture in Taiwan. Completion of this paper was aided by a grant from the Paramitas Foundation to J.S.H.

\section{References}

Ho, J. S., \& Kim, I. H. (2001). New species of Doridicola (Copepoda, Rhynchomolgidae) from Thailand, with a cladistic analysis of the genus. Journal of Crustacean Biology, 21, 78-89.

Humes, A. G. (1984). Copepods associated with the scleractinian coral Porites in French Polynesia. Cahiers de Biologie Marine, 25, 181-195.

Humes, A. G. (1985). A review of the Xarifiidae (Copepoda, Poecilostomatoida), parasites of scleractinian corals in the Indo-Pacific. Bulletin of Marine Science, 36, 467-632.

Humes, A. G., \& Gooding, R. U. (1964). A method for studying the external anatomy of copepods. Crustaceana, $6,238-240$.

Humes, A. G., \& Ho, J. S. (1968). Xarifiid copepods (Cyclopoida) parasitic in corals in Madagascar. Bulletin of the Museum of Comparative Zoology, Harvard University, 136, 415-459.

Nair, B. U., \& Pillai, N. K. (1985). Three new species of copepods associated with south Indian invertebrates. Crustaceana, 50, 27-38. 